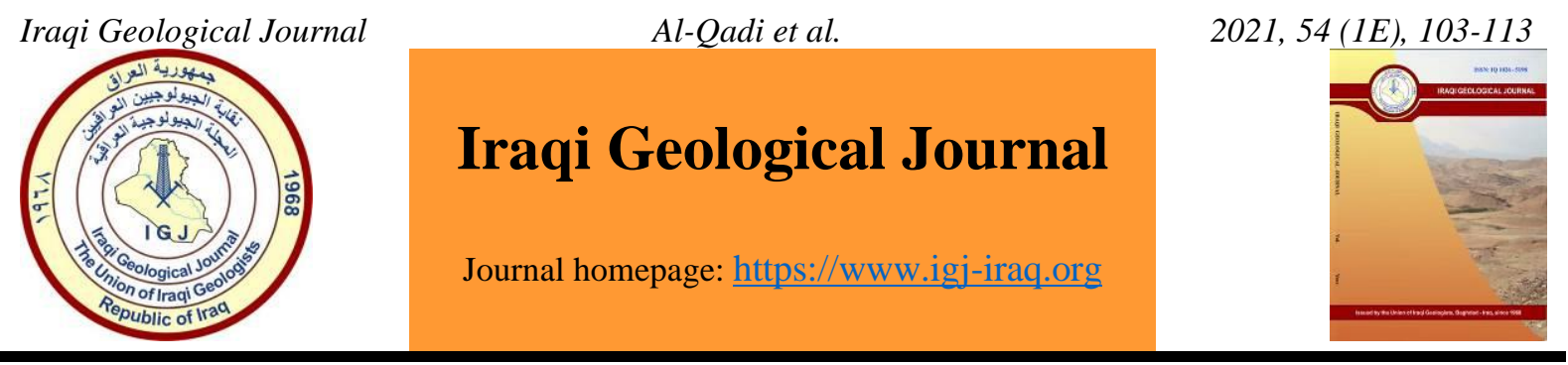

\title{
Analysis of Correlation and Coupling between El Niño-Southern Oscillation and Dust Storms in Iraq from 1971 to 2016
}

\author{
Tagreed Ahmed Al-Qadi1,", Khamis Daham Muslih ${ }^{1}$, and Alyaa Gatea Shiltagh² \\ ${ }^{1}$ Department of Geography, College of Arts, University of Baghdad, Iraq \\ ${ }^{2}$ Department of Geography, College of Education, Mustansiriyah University, Iraq \\ *Correspondence: taghreedalqadi1 @ gmail.com
}

Received: 2 September 2021; Accepted: 24 March 2021; Published: 31 May 2021

\begin{abstract}
This study's main objective is to examine the impact of the El Niño-Southern Oscillation on dust storms in Iraq and trying to find a reasonable synoptic explanation of this relationship. In order to achieve our goal, various data collections related to dust storm days from eight stations in Iraq and the El Niño-Southern Oscillation data over the period 1971-2016 were analyzed. The results showed a negative relationship between dust storms and the El Niño-Southern Oscillation. This correlation means high dust storms are associated with La Niña, while the low dust storms occur during the El Niño event. The coupling between the tropical pacific sector and dust storms in Iraq is perhaps related to the El Niño-Southern Oscillation variations and how they can contribute to the change of the main pressure system values that mainly participate in triggering dust storms and their intensity. The subtropical high-pressure and the Indian monsoon low-pressure systems have been recognized as the responsible pressure systems for dust storms formation.
\end{abstract}

Keywords: El Niño-southern oscillation; Tropical pacific ocean; Dust storms; Synoptic patterns; Iraq

\section{Introduction}

Dust storms are actively an important phenomenon that can modify the global climate system, including the impact on the solar and ground radiation and water balances as well as their severe social and health effects. Dust storms are defined by the World Meteorological Organization (WMO) as events in which visibility is reduced at eye level $(1.8 \mathrm{~m})$ to less than $1000 \mathrm{~m}$ with winds speed exceeding 33 $\mathrm{km} / \mathrm{h}$ (McTainsh and Pitblado, 1987). The Middle Eastern region is one of the world's most affected regions by dust storms, and it is the main dust storms source in the world (Hamidi et al., 2013; AlJumaily and Ibrahim, 2013; Notaro et al., 2015). The climate simulation models indicate that the percentage of dust emissions from the Middle East region estimated at $24 \%$ of total global dust emission (Ginoux et al., 2004). In Iraq, many dust storms are formed and developed per year due to part of its territory being desert, represented by the Western Desert and the Mesopotamia floodplain area. Furthermore, continental locations of Iraq put it through long periods of drought ranging from five to seven months annually. Also, the study area suffers from land degradation caused by the draining of the Marshlands, large-scale military operations, increased mining activities, oil extraction, construction, and urbanization. All these factors with strong and turbulent wind led to raising large quantities of dust into

DOI: $\underline{10.46717 / i g j .54 .1 E .9 M s-2021-05-30}$ 
the air (Al-Qadi, 2001; Al-Jumaily and Ibrahim, 2013; Rasheed and Al-Ramahi, 2021). Many studies have been conducted to analyse dust storms and their relationship to the Middle East Region. Hamidi et al. (2013) analysis the synoptic pattern associated with dust events over the Middle East and south-west Asia. The result showed good opportunities for dust storms to form when low-pressure over Iran and sub-tropical high-pressure systems over the eastern Mediterranean developed well. Other studies have been made to examine the variations of dust storms in the desert areas of Syria, Iraq, Iran, Kuwait, and Saudi Arabia. The studies indicated a positive annual and seasonal trend across the south and southeastern regions, while a general downward trend was observed across the north and northwestern parts of the region (Al-Dousari et al., 2014; Namdari et al., 2018; Özdemir et al., 2018). Notaro et al. (2015) investigated the dust storms activities across the Arabian Peninsula during the period 2007-2013 and linked to the prolonged drought over the Fertile Crescent. In recent years, numerous studies have been conducted to determine the health and socioeconomic effects of dust storms in many countries in the Middle East Region (Thalib and Al-Taiar, 2012; Al-Hemoud et al., 208; Goudarzi et al., 2017; Sicard and Armin, 2017; Al-Hemoud et al., 2017).

In the case of Iraq, several studies have focused on analyzing dust storms events over the country and their spatial and temporal distributions. Al-Qadi (2001) analyzed the synoptic patterns that caused the formation of dust storms over Iraq. Al-Qadi suggested that the dust storms were mostly associated with low-pressure systems, and they became more frequent with ridges than troughs at $500 \mathrm{mb}$ level. However, Al-Qadi also found that at least 13 pressure systems influence the dust storms formation in the study area with different contribution rates.

The first pressure system is the Indian monsoon low-pressure, which causes about $50.4 \%$ of the total dust storms over Iraq because it prolongs and extends its dominance during the summer over Iraq. The Second is the Sudan thermal low (24.8\%), then Siberian high (7.3\%), Mediterranean cyclones (5.1\%), European high (3.9\%), local low-pressure systems (2.4\%), a sub-tropical cyclone, the Icelandic low, and the Azores high ( $0.9 \%$ ) for each one of them, the subtropical high (7\%), the Caspian low (0.5\%) and the Arabian Peninsula high (0.2\%). Al-Jumaily and Ibrahim (2013) studied the synoptic patterns leading to dust storms formation in Iraq and surrounding deserts based on analysis of the satellite images, aerosol's index, and synoptic weather maps. The results showed that the dust storms developed when a low-pressure was formed over Iran, causing Shamal winds to blow toward the south. Sissakian et al. (2013) analyzed the sand and dust storms in Iraq. The study pointed out that the frequency of dust storms has increased drastically in the last decade. According to this study, the main reasons for the development of sand and dust storms over Iraq are the climate changes in the region, represented by decreased annual rainfall rate as well as other environmental changes, such as drying of the marshland, land degradation, and desertification (Beg and Al-Sulttani, 2020). Several studies have been conducted to link the El Niño-Southern Oscillation (ENSO) with some global and regionally climatic parameters. In the Middle East, many studies have been published; most of them focus on analysing the relationship between the ENSO and the Pacific Decadal Oscillation (PDO) with the precipitation and temperature variations in the Eastern Mediterranean region (Alpert et al., 2005; Price et al., 1998; Notaro et al., 2015; $\mathrm{Pu}$ and Ginoux, 2016).

Despite the numerous scientific studies concerned with the analysis of dust storms in Iraq, no study investigated the relationship between ENSO and dust storms over Iraq. Therefore, this study aims to analyze the statistical relationship between ENSO and the frequency of dust storms events over Iraq. Moreover, the study aims to explore the potential causal synoptic relationship between the ENSO events and dust storms, in a sense trying to determine the physical mechanisms through which the ENSO affects the formation and development of dust storms over Iraq. 


\section{Materials and Methods}

\subsection{Sources of Data}

The source of three sets of data was used in this paper includes the following;

- The monthly averages of dust storms for eight meteorological stations that provide data without interruption have been analyzed to achieve our goal. Unfortunately, some meteorological stations in Iraq have been excluded from this study because they did not work properly. In truth, they suffer from repeated interruptions of observation and could not submit the climate data regularly. Anyway, the eight meteorological stations were well geographically distributed over the study area, covering 46 years from 1971 to 2016 (Table 1 and Fig.1.) The eight stations are Mosul, Kirkuk, Baghdad, Najaf, Hai, Diwaniyah, Nasiriyah, and Basrah. All recorded dust storm data was obtained from the Iraqi Meteorological Organization.

Table 1. Details of the selected meteorological stations used in this study (Iraqi Meteorological Organization and Seismology)

\begin{tabular}{lcccc}
\hline Station & $\begin{array}{c}\text { Station } \\
\text { number }\end{array}$ & Latitude (N) & Longitude (E) & Altitude (m a.s.l) \\
\hline Mosul & 608 & $36^{\circ} 19^{\prime}$ & $43^{\circ} 09^{\prime}$ & 222.6 \\
Kirkuk & 621 & $35^{\circ} 28^{\prime}$ & $44^{\circ} 24^{\prime}$ & 330.8 \\
Baghdad & 650 & $33^{\circ} 29^{\prime}$ & $44^{\circ} 24^{\prime}$ & 34.1 \\
Hai & 665 & $32^{\circ} 10^{\prime}$ & $46^{\circ} 03^{\prime}$ & 17 \\
Najaf & 670 & $31^{\circ} 57^{\prime}$ & $44^{\circ} 19^{\prime}$ & 32 \\
Diwaniya & 672 & $31^{\circ} 59^{\prime}$ & $44^{\circ} 59^{\prime}$ & 20.4 \\
Nasiriya & 676 & $31^{\circ} 01^{\prime}$ & $46^{\circ} 14^{\prime}$ & 3 \\
Basrah & 689 & $30^{\circ} 34^{\prime}$ & $47^{\circ} 47^{\prime}$ & 2.4 \\
\hline
\end{tabular}

- The ENSO is recognized as the primary source for global climate variability after the annual climate circulation (Yang et al., 2018; Alpert et al., 2005). It is a dual periodic fluctuation represented in sea surface temperature (El Niño) and the atmospheric pressure (Southern Oscillation) across the equatorial Pacific Ocean. Sea surface temperature (SST) measurements are often used to determine the El Niño phenomenon (Rasmusson and Carpenter, 1982). The ENSO index used was the monthly and annual SST in the eastern tropical Pacific Ocean for the period (1971-2016). The SST index used is that El Niño 3 region located about $\left(5^{\circ} \mathrm{S}-5^{\circ} \mathrm{N}, 90^{\circ} \mathrm{W}-150^{\circ} \mathrm{W}\right)$ (Fig. 2). The ENSO events El Niño (La Niña) defined when SST anomalies exceed $+0.5^{\circ} \mathrm{C}\left(-0.5^{\circ} \mathrm{C}\right)$ for at least five sequential months (McGregor and Ebi, 2018).

- Daily geopotential heights of $850 \mathrm{hPa}$ were used for two periods (November 2015 to April 2016) and (November 1999 to April 2000).

In order to gain a stronger understanding and statistical accuracy of the relationship between the dust storms occurrences and ENSO index, the Pearson correlation coefficient has been utilized. The Pearson correlation test has been recognized as one of the most common methods for measuring reliance between two variables using the following equation (Rodgers and Nicewander, 1988). A correlation coefficient was taken to be statistically significant when the null hypothesis exceeded a probability level of $10 \%$. The significance of correlation values was tested at $1 \%, 5 \%$, and $10 \%$ levels. 
In the last section of this paper, the geopotential height anomaly pattern maps were created to recognize the physical mechanisms underlying the possible teleconnection between ENSO and dust storms over Iraq.

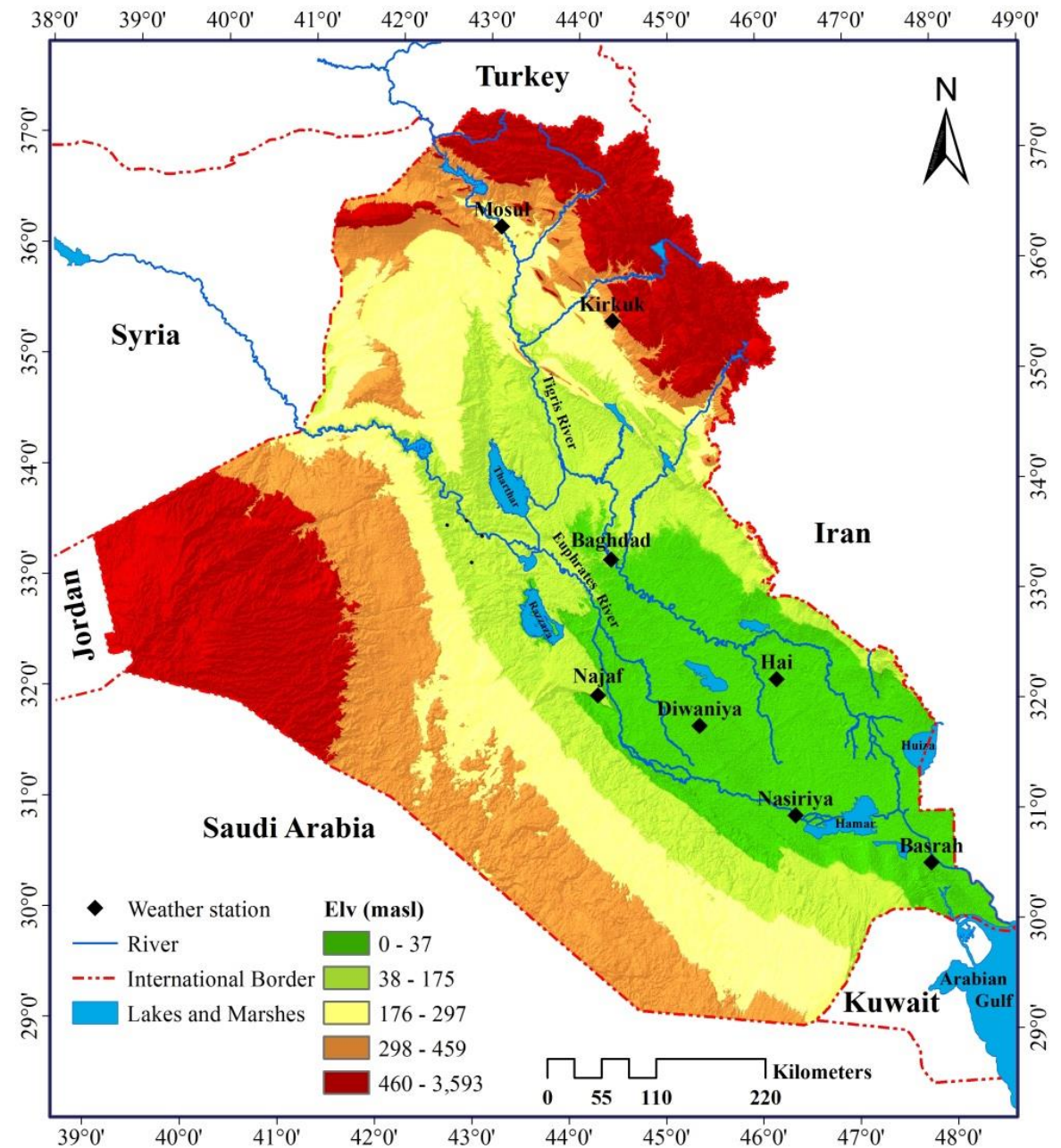

Fig.1. Physical map of Iraq with the spatial distribution of meteorological stations used in the paper

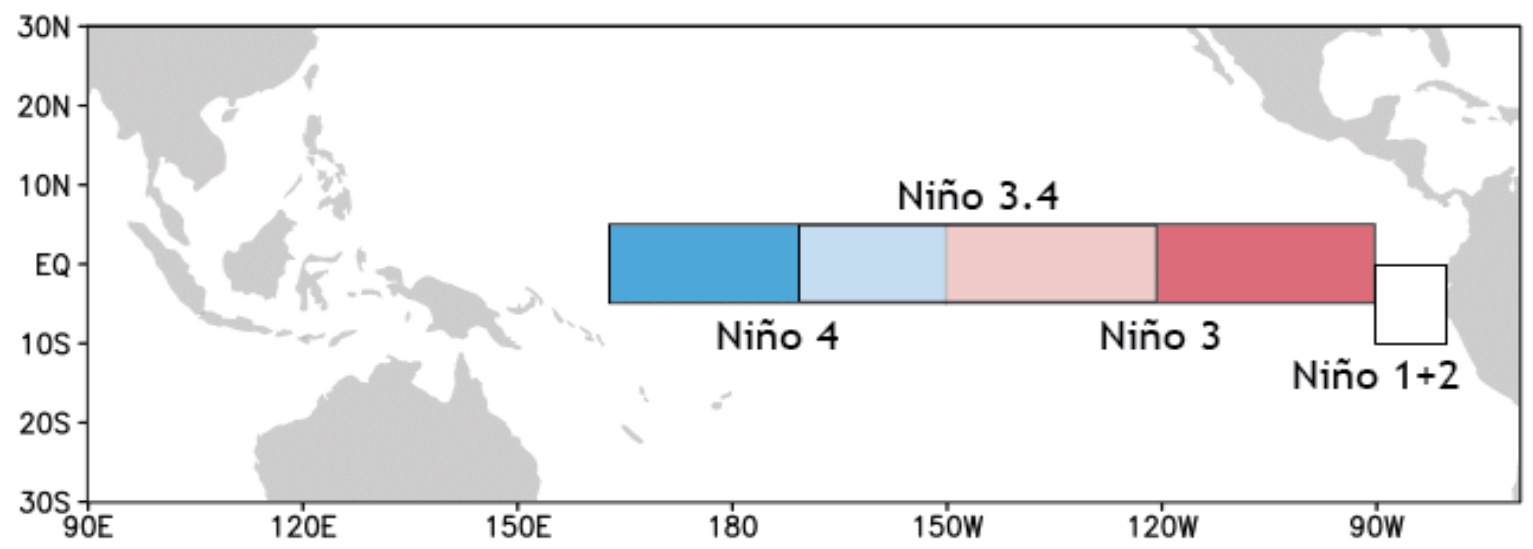

Fig.2. Location of the El Niño 3 region for measuring sea surface temperature in the eastern and central tropical Pacific Ocean. Source modified from Wang et al. 2016. 


\section{Results and Discussion}

\subsection{Dust Storms during the Period 1971-2016}

There are nearly 355 dust storms recorded in Iraq for 46 years (1971- 2016) as an average. Fig. 3 shows the total number of dust storms in selected metrological stations used in this study. It is obvious that dust storms can occur anywhere over the territory of Iraq but most likely occur over the Nasiriya station in the south of Iraq. A higher number of dust storms was registered (965) throughout the studied period. However, the lowest number of dust storms was observed in eastern areas of Iraq (76 and 94) in Kirkuk and Hai stations, respectively. Spatial variation of dust storms distribution may be attributed to many local and regional factors, including the decrease in the annual rate of precipitation, land degrading, desertification, and military operations, mainly in the southern desert of Iraq (Sissakian et al. 2013).

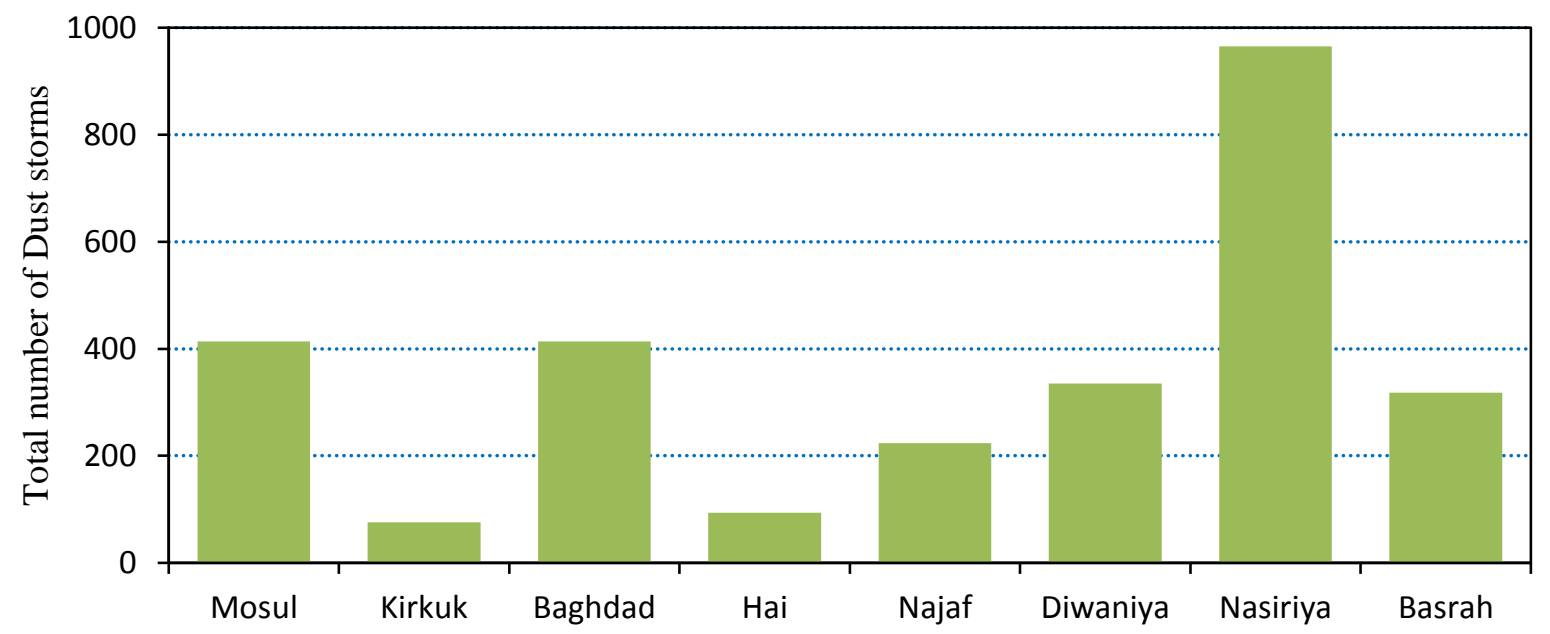

Fig. 3. Number of dust storms per selected meteorological station in Iraq for the period (1971-2016)

\subsection{Link between ENSO and Dust Storms in Iraq}

Recent studies on teleconnection pattern, which were carried out in the Middle East region, including Iraq, have shown that the climate condition in the Middle East region is highly sensitive to any changes or fluctuations in ENSO index (Alpert et al., 2005; Price et al.,1998; Al-Khalidi et al., 2018; $\mathrm{Pu}$ and Ginoux, 2016). This section of the research is devoted to analyzing the direct relationship between ENSO and dust storms over Iraq. Fig. 4 shows the time series of the relationship between the ENSO and the total annual frequency of dust storms over Iraq during the period 1971-2016 represented by eight meteorological stations. The exact figure shows that the correlation is not entirely evident, but it tends to be a negative relation during most time series. As El Niño phenomenon intensifies more, the dust storms frequencies over Iraq decline. Fig.4-B explains the relationship between anomalies of the ENSO index and anomalies in the annual average of dust storms over Iraq. the years 1973, 1983, 1992, 1995, 1998, and 2016 recorded the highest El Niño index values. Nevertheless, the highest single recorded El Niño index was in 2016 at index values 1.8, 2.2, 1.7, 1, 2.2, 2.5, respectively (Fig. 4). On the other hand, most of these years recorded the lowest values of annual average dust storms over Iraq, especially in 1995, 1998, and 2016 which confirmed the negative correlation and became even stronger since the beginning of the last century. Perhaps this is due to the ENSO indices becoming increasingly volatile and dissimilar and as shown in Fig. 4 that represented the frequency of intense El Niño events during this period. It is worth mentioning that this period coincides with the warm periods we are currently living in, where the temperature in Iraq started to rise dramatically since the beginning of the 
nineties of the last century without retreat. The same period is also consistent with the average global temperature trend (Muslih and Błażejczyk, 2017).

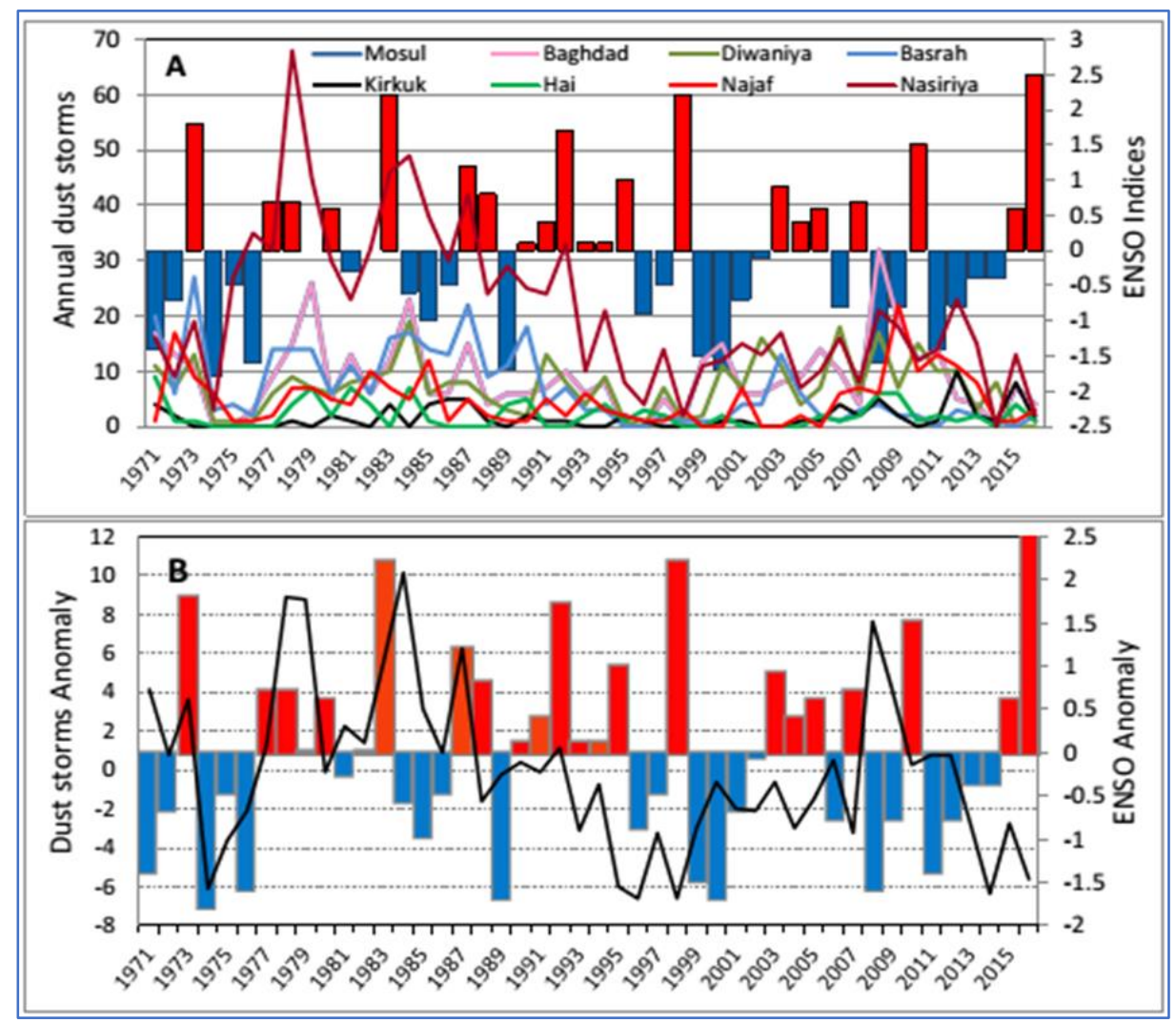

Fig.4. Time series correlation between the ENSO indices and dust storms over Iraq and time series correlation between anomalies of the ENSO indices and anomalies in the annual average of dust storms Iraq black line

The indirect relations between ENSO index and precipitation and temperature over Iraq have been examined by Al-Khalidi et al. (2018). The study pointed that the precipitation and temperature variability during winter and spring are strong linked with ENSO. A positive correlation was found between El Niño and precipitation in the eastern Mediterranean region and its impact on the discharge of the Jordan River and lake level, where increased precipitation during the wintertime that associated with El Niño events (Price et al., 1998). Price et al. (1998) found that this strong positive, statistically significant relationship appeared only since the mid-1970. According to Price et al. (1998), these changes in correlation significant after and before mid-1970 due to long-term variations in the global system and shift in the average of jet stream position during the northern hemisphere.

In contrast, Fig.4 shows the decadal variations are more evident than those occurring annually. During the periods (1974-1977), (1988 - 2007) and (2012-2016) the dust storms were relatively weak, where negative anomalies were recorded annually and frequently based on the average over the years from 1971 to 2016. Association with positive anomalies of the ENSO indices for most cases means its frequency is higher than the general average for 1971-2016. This negative correlation stereotype can be seen clearly, as have already explained before, since the post-1990 relative to the prior period. Moreover, the researcher tried to examine the monthly correlation between the ENSO indices and the monthly average of dust storms for the eight stations distribution over Iraqi territory using Pearson's correlation coefficient. The results are summed up in Table 2 and Fig.5. The correlation test results show no clear tendencies of statistically significant monthly correlation between ENSO indices and dust storms. About $47.8 \%$ of the months have a negatively correlated, while more than half of the cases positively correlate. 
There were five months (September, November, December, January, and May) that recorded negative correlations with the ENSO indices as a prevailing relationship, explaining about $73.7 \%$ of the total cases that shown in Table 2. On the other hand, approximately $73 \%$ of the cases in the months (February, March, April, June, July, and October) have a positive correlation.

Table 2. Monthly correlation values between the ENSO indices and the dust storms over Iraq as estimated by person correlation statistic test over the period (1971-2016)

\begin{tabular}{|c|c|c|c|c|c|c|c|c|c|c|c|c|}
\hline Station & Jan & Feb & Mar & Apr & May & Jun & Jul & Aug & Sep & Oct & Nov & Dec \\
\hline Mosul & - & 0.222 & -0.036 & 0.211 & 0.012 & -0.19 & -0.241 & -0.219 & 0.129 & 0.062 & -0.177 & -0.073 \\
\hline Kirkuk & -0.091 & -0.144 & 0.058 & 0.077 & -0.171 & -0.091 & -0.14 & -0.077 & -0.283 & 0.02 & -0.065 & 0.069 \\
\hline Baghdad & -0.09 & 0.164 & 0.158 & 0.128 & -0.021 & 0.048 & 0.121 & 0.025 & -0.184 & 0.028 & -0.016 & -0.276 \\
\hline Najaf & -0.016 & 0.161 & 0.278 & 0.104 & -0.062 & 0.146 & 0.081 & 0.119 & -0.025 & 0.073 & -0.045 & $-0.388 *$ \\
\hline Hai & -0.015 & 0.105 & 0.189 & 0.104 & -0.003 & 0.214 & 0.059 & -0.159 & -0.171 & -0.086 & -0.101 & - \\
\hline Diwaniya & -0.015 & 0.077 & 0.219 & 0.146 & -0.215 & 0.24 & 0.159 & 0.093 & -0.272 & -0.27 & -0.141 & -0.299 \\
\hline Nasiriya & 0.179 & 0.239 & 0.088 & -0.042 & -0.095 & -0.05 & -0.145 & 0.018 & 0.061 & 0.238 & 0.035 & 0.045 \\
\hline Basrah & 0.081 & 0.002 & -0.036 & -0.047 & -0.071 & 0.03 & 0.16 & -0.024 & -0.071 & 0.049 & 0.168 & 0.213 \\
\hline
\end{tabular}

A significance level of $90 \%$ is marked by bold-underlined and a significance level of $95 \%$ - by bold-underlined and star. Furthermore, to the lacking clarity of the general tendency of the relationship between ENSO indices and the dust storms, most of the correlations were statistically insignificant except for eight cases out of 94 cases. Those eight cases have statistically significant correlation accounted about $8.51 \%$ of the total number of cases. Meanwhile, Table 2 shows six of the eight cases with a negative statistical significance correlation, and half of those cases occurred in December. Knowing that the El Niño events peaked during the period (December, January, and February), as mentioned previously in this study, this gives us a clear indication of the negative relationship between the ENSO indices and the dust storms over Iraq.

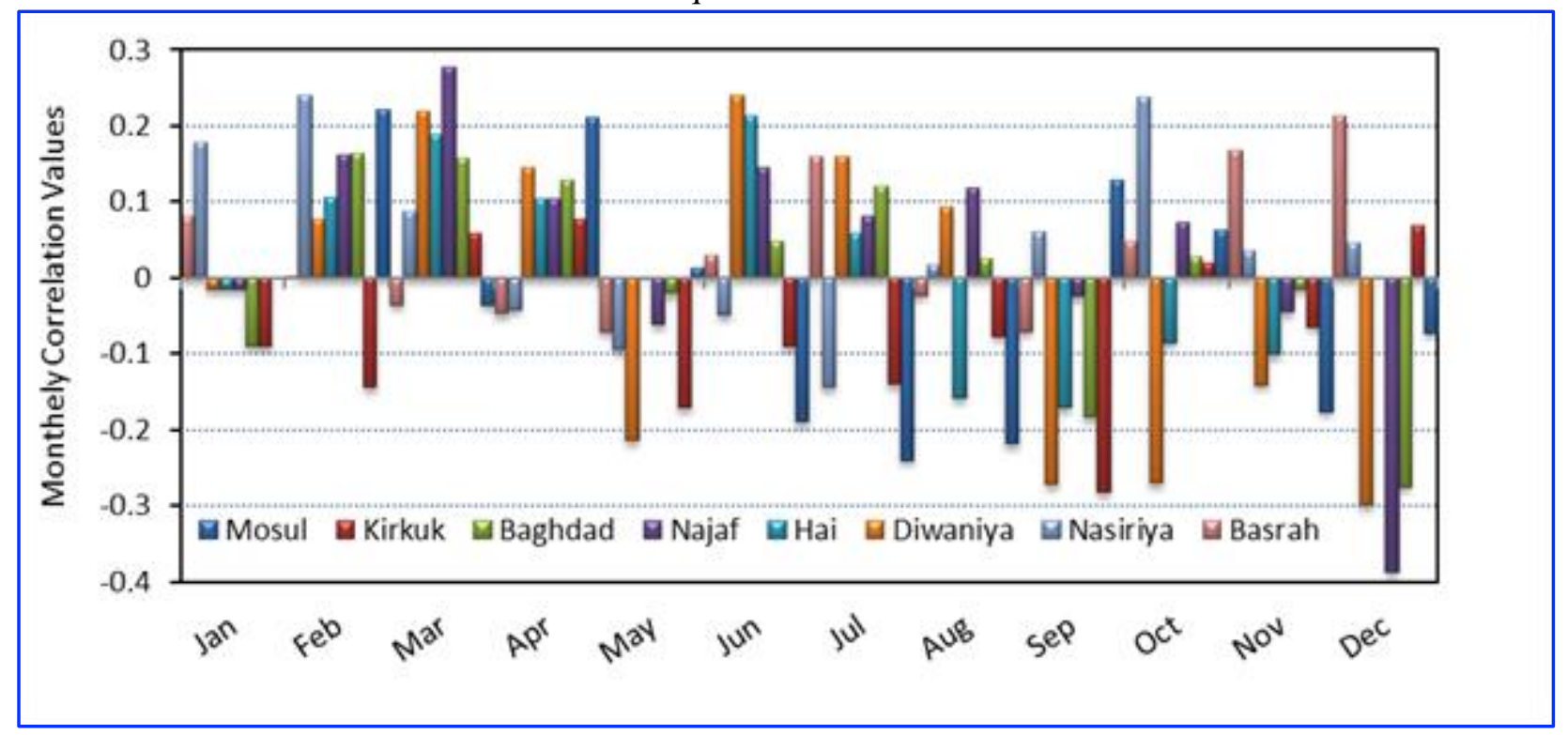

Fig.5. Values of monthly correlation between the ENSO indices and dust storms over Iraq (19712016)

Spatially, only central Iraq correlates with statistical significance. Simultaneously, the metrological stations in the north and south of Iraq did not record any statistically significant correlation (negative or positive) between a dust storm and ENSO indices. However, the highest value of negative correlation with statically significant was recorded in the Diwaniya station in September, October, and December 
at $(-0.272,-0.27$, and -0.299 , respectively). Our results were confirmed previously by several studies on the regional scale. For example, Pu and Ginoux (2016) study indicated that the negative correlation between ENSO and dust storms in Syria is less statistically significant than the correlation value recorded in the same study between dust storms and the PDO. The researchers returned the strong role of PDO in dust storms formed over Syria compared with the role of ENSO to; the PDO can be considered as a phenomenon driven by multiple physical processes more than those that affect the ENSO, including the tropical Pacific SST, Aleutian low, atmospheric noise, Rossby wave breaking, etc. (Pu and Ginoux, 2016). Another study also found a comparable correlation between precipitation over the Fertile Crescent (Syria and Iraq) and ENSO (-0.57) from 1979 to 2013 (Notaro et al.,, 2015). The relationship between the eastern Mediterranean region precipitation and ENSO is well investigated by many studies (Alpert et al., 2005). Most of these studies showed that the precipitation over the eastern Mediterranean region increases with the El Niño events and decreases with La Niña events.

\subsection{The Synoptic Coupling Mechanism between ENSO and Dust Storms over Iraq}

As previously mentioned, there is no significant correlation between ENSO and dust storms over Iraq. However, there is a general tendency to a negative correlation, especially in the period that followed the last century's nineties. Despite several studies dealing with the analysis of the synoptic patterns associated with the major dust storms events that stroked the Middle East region, including Iraq. Most of these studies attempted to determine the pressure patterns responsible for forming dust storms. Some of these studies mentioned that at least 13 atmospheric pressure systems are responsible for generating dust storms (Al-Qadi, 2001). All these studies confirmed that the main pressure system responsible for dust storms formation in the Middle East region is the Indian monsoon low, explaining between 50.4\% (Al-Qadi, 2001) to 68\% (Hamidi et al., 2013). That is related to the Indian monsoon low dominated over southern Iraq, Iran, the east of the Arabian Peninsula, and the Indian subcontinent, and it the subtropical High-Pressure zone located over the eastern Mediterranean and northern Africa to southern and eastern Europe. This will cause a great pressure gradient enhancing generated strong northwesterly winds that increase soil erosion and carry from the arid area of Syria, Iraq, northern Arabia, and Sahara. (Mohammed et al., 2015; Hamidi et al., 2013; Al-Jumaily and Ibrahim, 2013). During the positive phase of ENSO "El Niño event" the positive anomalous geopotential height at 850 $\mathrm{hPa}$ was observed over the Indian Ocean, Arabian Peninsula, Iran, and areas towards southern Iraq pressure values are higher than the general levels Fig.6-A. That is due to rising ocean water temperature always followed by a substantial modification of the general circulation patterns and global pressure patterns. This synoptic situation reduces the pressure gradient between the Indian monsoon low-pressure zone between $23^{\circ} \mathrm{N}$ and $48^{\circ} \mathrm{N} ; 50^{\circ} \mathrm{E}$ to $70^{\circ} \mathrm{E}$ and the subtropical high-pressure zone in the eastern Mediterranean toward North Africa region. Thus, the soil erosion operation would be less active due to the reduced pressure gradient, which led to a weaker wind speed than normal. This type of reduction in the number and intensity of dust storms over Iraq associated are with El Niño event activates. It is also supported by the fact that El Niño event is usually associated with heavy precipitation over the Middle East region due to changes in the upper atmospheric pressure pattern (Price et al., 1998; Alpert et al., 2005). Increased precipitation leads to a relative increase in vegetation cover and reduces the opportunity of dust erosion, as there is always a positive relationship between rainfall and vegetation cover (Mzuri et al., 2021).In the negative phase of ENSO “La Niña event," the negative anomalous geopotential height at $850 \mathrm{hPa}$ was dominated over the Indian Ocean and subcontinent, adjacent areas of southern Iran, Iraq, and Arabian Peninsula (Fig. 6). That means subtropical high pressure over the Eastern Mediterranean and North Africa and the Indian monsoon low over the Indian Ocean, Arabian Peninsula, Iran, and along areas towards southern Iraq were well developed, with anomalous pressure core higher and lower than normal, respectively. This synoptic situation creates a strong pressure gradient leading to accelerating 
the surface wind speed. Higher wind speed provided a unique opportunity to carry large amounts of dust particles from arid areas that stretching from Iraq, Syria, and North Africa to the northwest of the Arabian Peninsula. Moreover, a negative correlation between La Niña event activity and the Eastern Mediterranean precipitation decreased precipitation whenever the La Niña's activities occurred. A reduction in rainfall amounts to an increase of soil dryness and declining vegetation cover with an increase of surface wind flow that can carry dry and eroded soil from arid areas.

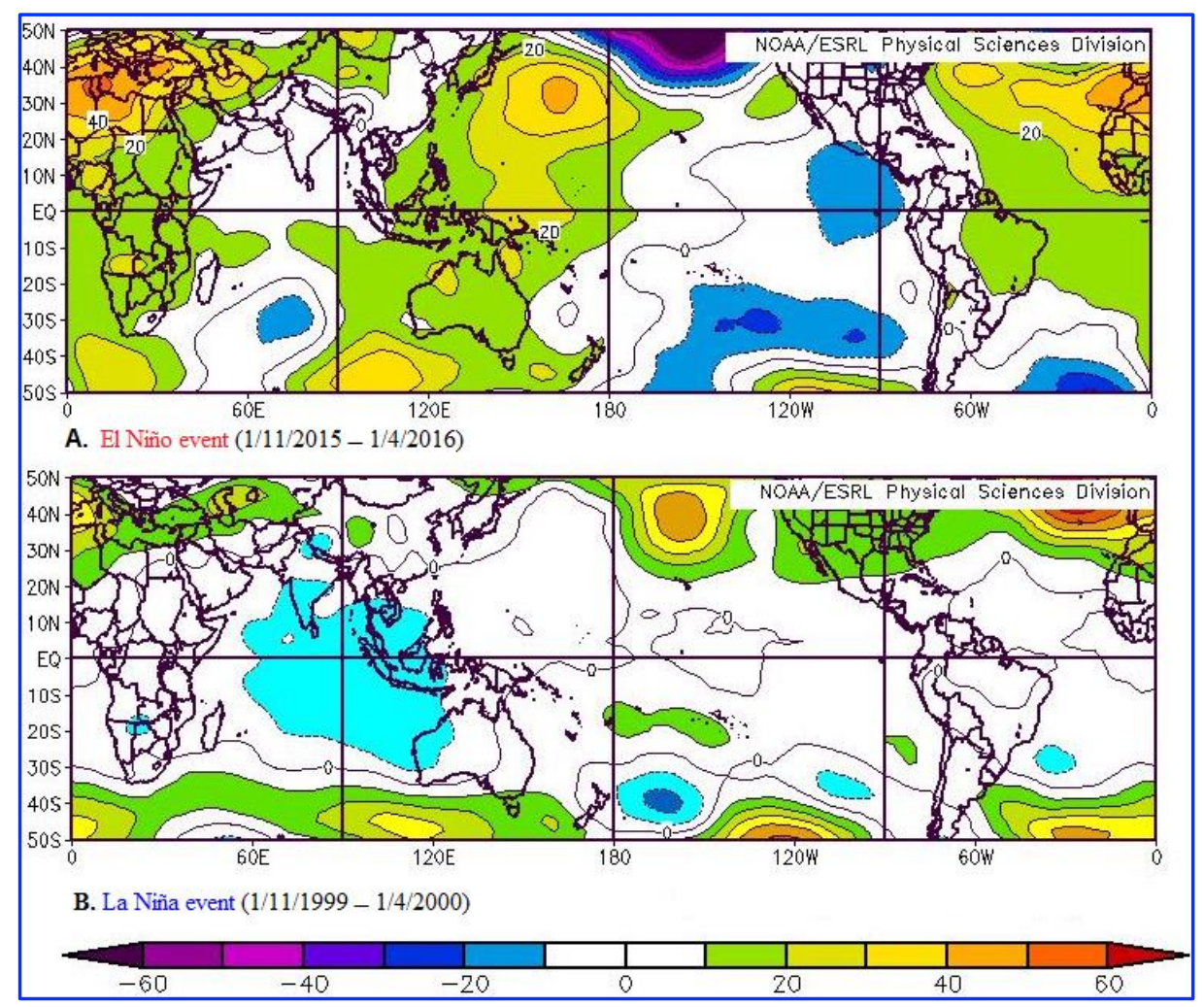

Fig. 6. A. Geopotential heights anomaly patterns for the 2015-2016 El Niño (anomalies averaged from November 2015 to April 2016); B. Geopotential heights anomaly patterns for the 1999 - 2000 La Niña (anomalies averaged from November 1999 to April 2000)

\section{Conclusions}

This paper seeks to investigate the relationship between the dust storms and the ENSO indices. It also aims to understand physical coupling mechanisms between the Southern Pacific and the pressure systems over the Middle East region (including Iraq). The results indicated that a correlation is found between the dust storms over Iraq and ENSO. Despite this correlation not being strong, it tended to be negative in many parts of time series and became more evident since the beginning of 1990 . This is probably due to the ENSO indices itself became increasingly volatile and more in variety, especially taking into account that the effect of the phenomenon is not direct, but its impacts occur through other pressure systems that are close to the region concerned, leaving significant effects on climate of Iraq. The monthly correlation test result showed that the months September, November, December, January, and May have a negative correlation. However, for the rest of the months (February, March, April, June, July, October), the correlation is very weak or tends toward a positive correlation. Spatially, statistically, significant correlations were found in central Iraq and completely disappeared in Mosul, Basrah, and Nasiriyah stations. The Diwaniyah station recorded the highest negative correlation value with statically significant in September, October, and December at (-0.272, -0.27 , and -0.299 , respectively). 
The synoptic coupling mechanism analysis showed that during El Niño event, the positive pressure anomalous at $850 \mathrm{hPa}$ was observed over the Indian Ocean, Arabian Peninsula, Iran, and areas towards southern Iraq. This synoptic situation reduces the pressure gradient between the Indian monsoons lowpressure system and the subtropical high-pressure system. So, there is less opportunity for dust storms to form when the surface wind weaker than normal. During the La Niña events, the negative pressure anomalous at $850 \mathrm{hPa}$ were observed over the Indian Ocean and subcontinent, adjacent areas of southern Iran, Iraq, and the Arabian Peninsula. Positive anomalous were found over the subtropical high pressure over the Eastern Mediterranean and North Africa. This synoptic situation creates a great pressure gradient between low and high-pressure systems, accelerating the surface wind speed and increasing the number and intensity of dust storms over Iraq).

\section{Acknowledgements}

The authors are very grateful to the Editor in Chief Prof. Dr. Salih M. Awadh, the Secretary of Journal Mr. Samir R. Hijab, and the Technical Editors for their great efforts and valuable comments. The authors would also like to thank Prof. Dr. Ahmed H. Al-Sulttani for his helpful guidance and valuable insights during the preparation of this manuscript.

\section{References}

Al-Hemoud, A., Al-Dousari, A., Al-Shatti, A., Al-Khayat, A., Behbehani, W., Malak M., 2018. health impact assessment associated with exposure to PM10 and dust storms in Kuwait. Atmosphere, 9 (1), 6.

Al-Hemoud, A., Al-Sudairawi, M., Neelamanai, S., Naseeb, A., Behbehani, W., 2017. Socioeconomic effect of dust storms in Kuwait. Arabian Journal of Geosciences, 10 (1), 18.

Al-Jumaily, K. J., Ibrahim, M. K., 2013. Analysis of synoptic situation for dust storms in Iraq. International Journal Energy Environment, 4 (5); 851-858.

Al-Khalidi, J., Dima, M., Stefan, S., 2018. Large-scale modes impact on Iraq climate variability. Theoretical Applied Climatology, 133,179-190.

Alpert, P., Price, C., Krichak, S. O., Ziv, B., Saaroni, H., Osetinsky, I., Barkan, J., Kishcha, P., 2005. Tropical teleconnections to the Mediterranean climate and weather. Advances in Geosciences, 2, 157-160.

Al-Qadi, T. A., 2001. The Impact of Upper and Surface Pressure Systems on the Creation of Dust Storms in Iraq. Ph.D dissertation (unpublished), University of Baghdad, College of Arts, Department of Geography, 217 pp.

Beg, A. A. F., Al-Sulttani, A. H., 2020. Spatial assessment of drought conditions over Iraq using the standardized precipitation index (SPI) and GIS techniques. In Environmental remote sensing and GIS in Iraq, Springer, Cham., 447-462.

Dousari, A., Al-Dousari, N., Ramadhan, A., Ahmed, M., Aba, A., 2014. Assessments of dust fallout within Kuwait. ProScience, 1, 149-155.

Ginoux, P., Prospero, J.M., Torres, O., Chin M., 2004. Long-term simulation of global dust distribution with the GOCART model: correlation with North Atlantic Oscillation. Environmental Modelling \& Software, 19(2), 113-128.

Goudarzi, G., Daryanoosh, S.M., Godini, H., Hopke, P.K., Sicard, P., De Marco, A., Rad, H.D., Habizadeh, A., Jahedi, F., Mohammadi, M.J., Savari, J., Sadeghi, S., Kaabi, Z., Khaniabadi, Y. O., 2017. Health risk assessment of exposure to the Middle-Eastern dust storms in the Iranian megacity of Kermanshah. Public Health, 148, 109-116.

Hamidi, M., Kavianpour, M. R., Shao, M., 2013. Synoptic Analysis of Dust Storms in the Middle East. AsiaPacific. Journal Atmospheric Science, 49(3), 279-286.

Iraqi Meteorological Organization and Seismology, Department of climate, monthly dust storms data for the period (1971-2016). (Unpublished data).

Khaniabadi, Y.O.; Daryanoosh, S.Y.; Amrane, A.; Polosa, R.; Hopke, P.K.; Goudarzi, G.; Mohammadi, M.J.; Sicard, P., Armin, H., 2017. Impacts of Middle Eastern dust storms on human health. Atmospheric Pollution Research, 8, 606-613. 
McGregor, G. R., Ebi, K., 2018. El Niño Southern Oscillation (ENSO) and health: an overview for climate and health researchers. Atmosphere, 9(7), 282.

McTainsh, G. H., Pitblado, J. R., 1987. Dust storms and related phenomena measured from meteorological records in Australia. Earth Surface Processes, 12, 415-424.

Mohammed, S. K., Al Fatla, N.M., Abdul Wahab, S. A., 2015. Analyzing the synoptic patterns associated to dust events over west Asia during summer months - Case Studies. IOSR Journal of Applied Physics, 7 (6), 5366.

Muslih, K. D., Błażejczyk, K., 2017. The inter-annual variations and the long-term trends of monthly air temperatures in Iraq over the period 1941-2013. Theoretical and Applied Climatology, 130, (1-2), 583596.

Mzuri, R. T., Omar, A. A., Mustafa, Y. T., 2021. Spatiotemporal analysis of vegetation cover and its response to terrain and climate factors in Duhok Governorate, Kurdistan Region, Iraq. Iraqi Geological Journal, 54(1), 110-126.

Namdari, S., Karimi, N., Sorooshian, A., Mohammadi, G., Sehatkashani, S., 2018. Impacts of climate and synoptic fluctuations on dust storm activity over the Middle East. Atmospheric Environment, 173, 265-276.

Notaro, M., Yu, Y., Kalashnikova, O. V., 2015. Regime shift in Arabian dust activity, triggered by persistent Fertile Crescent drought. Journal Geophysics Research Atmosphere, 120, 10229-10249.

Özdemir, E. T., Korkmaz, F. M., Yavuz, V., 2018. Synoptic analysis of dust storm over Arabian Peninsula: a case study on February 28, 2009. Nat Hazards, 92, 805-827

Price, C., Stone, L., Rajagopalan, B., Alpert, P.,1998. A possible link between El Nino and precipitation in Israel, Geophysics Research Letter, 25, 3963-3966.

Pu, B., Ginoux, P., 2016. The impact of the Pacific Decadal Oscillation on springtime dust activity in Syria. Atmospheric Chemistry and Physics, 16 (21), 13431-13448.

Rasheed, M. J., Al-Ramahi, F. K. M., 2021. Detection of the impact of climate change on desertification and sand dunes formation east of the tigris river in Salah Al-Din Governorate using remote sensing techniques. Iraqi Geological Journal, 54(1), 69-83.

Rasmusson, E. M., Carpenter, T. H. 1982. Variations in tropical sea surface temperature and wind associated with the southern Oscillation/El Niño. Monthly Weather Review, 110, 354-384.

Rodgers, J. L., Nicewander, W.A., 1988. Thirteen ways to look at the correlation coefficient. The American Statistician, 42 (1), 59-66.

Sissakian, V. K., Al-Ansari, N., Knutsson, S., 2013. Sand and dust storm events in Iraq. Natural Science, 5(10), 1084-1094.

Strahler, A. N., Strahler, A. H., 1974. Introduction to Environmental Science. Hamilton Publishing Company, U. S. A, 28 pp.

Thalib, L., Al-Taiar, A., 2012. Dust storms and the risk of asthma admissions to hospitals in Kuwait. Science of Total Environment, 433, 347-351.

Wang, C., Deser, C., Yu, J. Y., DiNezio, P., Clement, A., 2016. El Niño and Southern Oscillation (ENSO): A Review. Glynn, P., Manzello, D., and Enochs, I., (eds.), Coral Reefs of the Eastern Tropical Pacific, Coral Reefs of the World 8, Springer Science Publisher, 85-106.

Yang, S., Li, Z., Yu, j., Hu, X., Dong, W., He, S., 2018. El Niña -Southern Oscillation and its impact in the changing climate. National Science Review, 5, 840-857. 